\title{
Further Tiling Patterns Involving Islamic Rosettes with an Odd Number of Vertices
}

\author{
T.Gangopadhyay \\ XLRI \\ C.H.Area(E), Jamshedpur, \\ India
}

\begin{abstract}
Islamic rosette patterns have been extensively studied for their symmetry and aesthetic appeal. This paper presents several new tiling patterns that involve rosettes with an odd number of vertices.

\section{General Terms}

Islamic, Art, Pattern, Algorithm, Turbo C++, Program.

\section{Keywords}

Polygon, Rosette, Star, Symmetry, Trigonometric,

\section{INTRODUCTION}

Owing to their symmetry and aesthetic appeal, Islamic star and rosette patterns have been studied extensively by several researchers(Gr"unbaum and Shephard [8], Abas and Salman [1], Bourgoin[ ],Dewdney [5], Castera [3], Dunham[6]). The innate symmetry of these structures have led to geometrical constructions of these as well as tiling designs devised through putting such structures in contact(Castera [4], Gr"unbaum and Shephard[7], Kaplan[13]. Kaplan[12] has devised an elaborate construction method for stars based on methods described originally by Henkin [11] and Lee [14]. In addition Kaplan[13] has also devised a number of interesting tiling methods by putting stars in contact. Most of these tiling styles use stars and rosettes with an even number of vertices. Tiling with stars having an odd number of vertices have been studied by Gangopadhyay([9],[10]). In yet another paper(Gangopadhyay[11]), a simpler method to construct a rosette is described along with several new generalized tiling methods which use rosettes with both even and odd number of vertices. In this paper further new generalized tiling methods are devised which use rosettes with any number of vertices. This is the distinguishing feature of this paper.
\end{abstract}

\section{HOW TO DRAW A ROSETTE}

The construction of a generalized rosette, denoted as rosette(n,k,k0,k1,k2) has been described in detail in Gangopadhyay[11]. Every rosette(n,k,k0,k1,k2) embeds a star(n,k,k0). Figure 1 below illustrates osette $(11,75,30,105,150)$. The embedded $\operatorname{star}(11,75,30)$ is presented in cyan color.

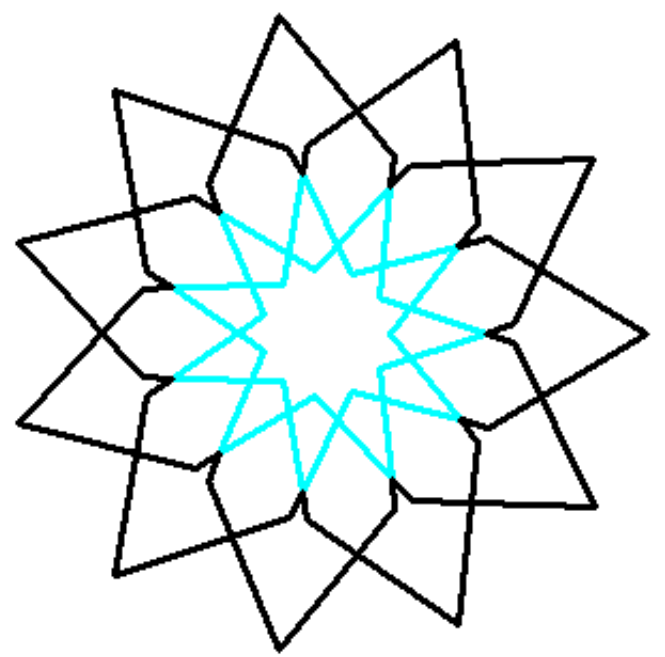

Fig 1 : rosette(11,75,30,105,150).

\section{TILING WITH ROSETTES}

The process of tiling is illustrated for rosette $(11,50,20,70,100)$. The basic prototype is a double rosette which is shown in Figure 2 and is drawn as follows. First rosette $(11,50,20,70,100)$ is drawn with its center coordinates at $\mathrm{i}$ and $\mathrm{j}$. Then another rosette $(11,50,20,70,100)$. is drawn by aligning the qth vertex of the old star with the pth vertex of the new one in such a manner that the line joining the center of the star with its pth vertex in the new star is parallel to the similar line in the old one, where the integer $\mathrm{p}=$ $\mathrm{n}+1-\mathrm{n}(\bmod 3)$ and $\mathrm{q}=(\mathrm{n}+1) / 2-((\mathrm{n}-7) / 4)(\bmod 2)$. This basic prototype of two aligned stars is displayed in Figure 2. 


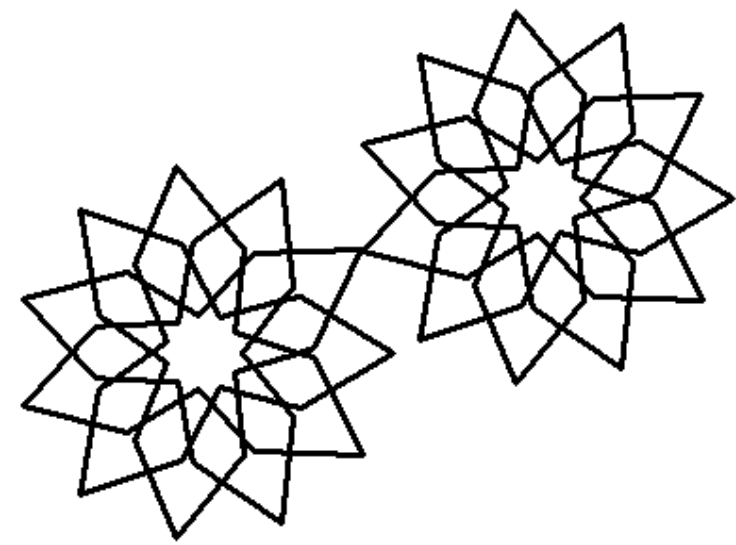

Fig. 2 : The Prototype - two aligned rosettes

The image in Figure 2 is then repeated by increasing the center coordinates of rosette $(11,50,20,70,100)$.. at an interval of $\quad 2(\mathrm{k} 2) \cos (2 \pi \mathrm{p} / \mathrm{n})-2(\mathrm{k} 2) \cos (2 \pi \mathrm{q} / \mathrm{n})$ for the abscissa $\mathrm{i}$ and $2(\mathrm{k} 2) \sin (((\mathrm{n}+1) / 4)$ angle $) \pi / 180)$ for the ordinate j.where angle $=360 / \mathrm{n}$.

The final output is shown in Figure 3

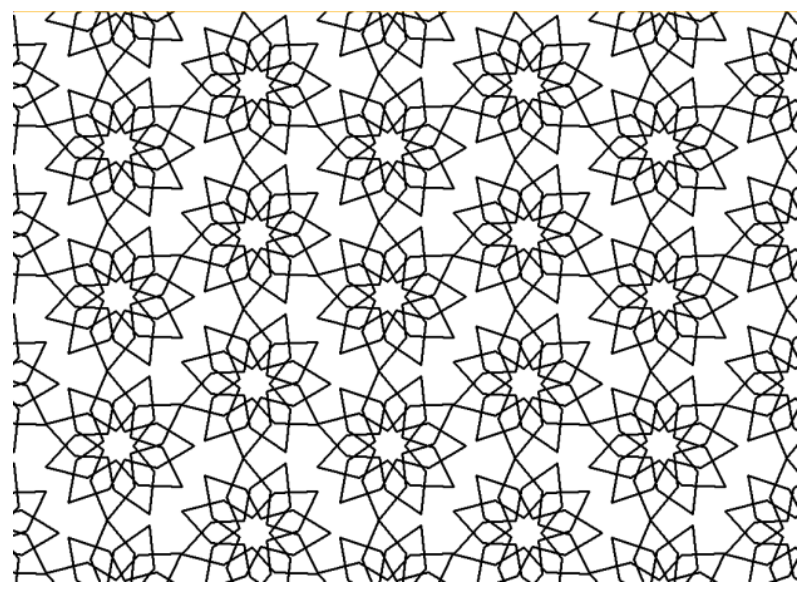

Fig 3 : The final output of tiling

The algorithm described in sections 2 and 3 is presented in the form of the $\mathrm{C}++$ code in section 4 .

\section{THE CODE}

The code uses three functions interx, intery and rose which are declared first..The functions interx and intery respectively returns the abscissa and ordinate of the line passing through points $(\mathrm{x} 1, \mathrm{y} 1)$ and $(\mathrm{x} 2, \mathrm{y} 2)$ and the one passing through the points $(\mathrm{x} 3, \mathrm{y} 3)$ and $(\mathrm{x} 4, \mathrm{y} 4)$, while the function rose draws rosette $(\mathrm{n}, \mathrm{k}, \mathrm{k} 0, \mathrm{k} 1, \mathrm{k} 2)$. float interx(float x1,float y1,float x2,float y2,float x3,float $\mathrm{y} 3$,float $\mathrm{x} 4$,float $\mathrm{y} 4$ )

$\{$ return $(\mathrm{y} 3-\mathrm{y} 1-\mathrm{x} 3 *(\mathrm{y} 4-\mathrm{y} 3) /(\mathrm{x} 4-\mathrm{x} 3)+\mathrm{x} 1 *(\mathrm{y} 2-\mathrm{y} 1) /(\mathrm{x} 2-$ $\mathrm{x} 1)) /((\mathrm{y} 2-\mathrm{y} 1) /(\mathrm{x} 2-\mathrm{x} 1)-(\mathrm{y} 4-\mathrm{y} 3) /(\mathrm{x} 4-\mathrm{x} 3)) ;\}$

float intery(float $\mathrm{x}$ 1,float $\mathrm{y}$,float $\mathrm{x} 2$,float $\mathrm{y}$,float $\mathrm{x}$,float y3,float x4,float y4)

$\{$ return $(\mathrm{x} 3-\mathrm{x} 1-\mathrm{y} 3 *(\mathrm{x} 4-\mathrm{x} 3) /(\mathrm{y} 4-\mathrm{y} 3)+\mathrm{y} 1 *(\mathrm{x} 2-\mathrm{x} 1) /(\mathrm{y} 2-$ $\mathrm{y} 1)) /((\mathrm{x} 2-\mathrm{x} 1) /(\mathrm{y} 2-\mathrm{y} 1)-(\mathrm{x} 4-\mathrm{x} 3) /(\mathrm{y} 4-\mathrm{y} 3)) ;\}$

void rosefloat $\mathrm{k}$,float $\mathrm{k} 0$,float $\mathrm{k} 1$,float $\mathrm{k} 2$,int $\mathrm{n}$,int $\mathrm{x} 0$,int $\mathrm{y} 0$ )

\{float

$\mathrm{x}[100], \mathrm{y}[100], \mathrm{xx}[100], \mathrm{yy}[100], \mathrm{xz}[100], \mathrm{yz}[100], \mathrm{xx} 0[100], \mathrm{yy} 0$ [100],xx1[100],yy1[100],u[100],v[100],u0[100],v0[100];

for (int $\mathrm{i}=0 ; \mathrm{i}<\mathrm{n} ; \mathrm{i}++)$

$\{\mathrm{x}[\mathrm{i}]=\mathrm{k} * \cos (2 * 3.14 * \mathrm{i} / \mathrm{n})+\mathrm{x} 0$;

$\mathrm{y}[\mathrm{i}]=\mathrm{k} * \sin (2 * 3.14 * \mathrm{i} / \mathrm{n})+\mathrm{y} 0$;

\}

for $($ int $\mathrm{i}=0 ; \mathrm{i}<\mathrm{n} ; \mathrm{i}++)$

$\{\mathrm{xx} 0[\mathrm{i}]=\mathrm{k} 1 * \cos (2 * 3.14 *(\mathrm{i}+.5) / \mathrm{n})+\mathrm{x} 0$;

yy $0[\mathrm{i}]=\mathrm{k} 1 * \sin (2 * 3.14 *(\mathrm{i}+.5) / \mathrm{n})+\mathrm{y} 0$;

\}

for(int $\mathrm{i}=0 ; \mathrm{i}<\mathrm{n} ; \mathrm{i}++)$

$\{\mathrm{xx} 1[\mathrm{i}]=\mathrm{k} 2 * \cos (2 * 3.14 *(\mathrm{i}) / \mathrm{n})+\mathrm{x} 0$;

yy $1[\mathrm{i}]=\mathrm{k} 2 * \sin (2 * 3.14 *(\mathrm{i}) / \mathrm{n})+\mathrm{y} 0$;

\}

for $($ int $\mathrm{i}=0 ; \mathrm{i}<\mathrm{n} ; \mathrm{i}++)$

$\{\mathrm{xx}[\mathrm{i}]=\mathrm{k} 0 * \cos (2 * 3.14 * \mathrm{i} / \mathrm{n})+\mathrm{x} 0$;

$\mathrm{yy}[\mathrm{i}]=\mathrm{k} 0 * \sin (2 * 3.14 * \mathrm{i} / \mathrm{n})+\mathrm{y} 0 ;\}$

for(int $\mathrm{i}=0 ; \mathrm{i}<\mathrm{n} ; \mathrm{i}++)$

\{

line $(x x[i], y y[i], x[(i-1+n) \% n], y[(i-1+n) \% n])$;

line $(x x[i], y y[i], x[(i+1) \% n], y[(i+1) \% n])$;

\}

for(int $\mathrm{i}=0 ; \mathrm{i}<\mathrm{n} ; \mathrm{i}++)$

\{

$\mathrm{u}[\mathrm{i}]=\operatorname{interx}(\mathrm{x}[\mathrm{i}], \mathrm{y}[\mathrm{i}], \mathrm{xx}[(\mathrm{i}+1) \% \mathrm{n}], \mathrm{yy}[(\mathrm{i}+1) \% \mathrm{n}], \mathrm{xx} 0[(\mathrm{i}-$ $1+n) \% n], y y 0[(i-1+n) \% n], x x 1[(i-1+n) \% n], y y 1[(i-1+n) \% n])$;

$\mathrm{v}[\mathrm{i}]=\operatorname{intery}(\mathrm{x}[\mathrm{i}], \mathrm{y}[\mathrm{i}], \mathrm{xx}[(\mathrm{i}+1) \% \mathrm{n}], \mathrm{yy}[(\mathrm{i}+1) \% \mathrm{n}], \mathrm{xx} 0[(\mathrm{i}-$ $1+n) \% n], y y 0[(i-1+n) \% n], x x 1[(i-1+n) \% n], y y 1[(i-1+n) \% n])$;

$\mathrm{u} 0[\mathrm{i}]=\operatorname{interx}(\mathrm{x}[\mathrm{i}], \mathrm{y}[\mathrm{i}], \mathrm{xx}[(\mathrm{i}-1+\mathrm{n}) \% \mathrm{n}], \mathrm{yy}[(\mathrm{i}-$

$1+\mathrm{n}) \% \mathrm{n}], \mathrm{xx} 0[(\mathrm{i}) \% \mathrm{n}], \mathrm{yy0}[(\mathrm{i}) \% \mathrm{n}], \mathrm{xx} 1[(\mathrm{i}+1) \% \mathrm{n}], \mathrm{yy} 1[(\mathrm{i}+1) \% \mathrm{n}])$

v0[i]=intery $(x[i], y[i], x x[(i-1+n) \% n], y y[(i-$

$1+\mathrm{n}) \% \mathrm{n}], \mathrm{xx} 0[(\mathrm{i}) \% \mathrm{n}], \mathrm{yy0}[(\mathrm{i}) \% \mathrm{n}], \mathrm{xx} 1[(\mathrm{i}+1) \% \mathrm{n}], \mathrm{yy} 1[(\mathrm{i}+1) \% \mathrm{n}])$ ;

line $(u[i], v[i], x[(i) \% n], y[(i) \% n]) ; l i n e(u[i], v[i], x x 1[(i-$ $1+n) \% n], y y 1[(i-1+n) \% n])$; 
line(u0[i],v0[i],x[(i)\%n],y[(i)\%n]);line(u0[i],v0[i],xx1[(i+1)\% $\mathrm{n}], \mathrm{yy} 1[(\mathrm{i}+1) \% \mathrm{n}])$;

\section{\} \\ \}}

void main()

\{

initwindow(1040,760);

int $1=20$;

int $\mathrm{k}=2.5 * 1$;int $\mathrm{n}=11$;float ang=360./n;float $\mathrm{k} 0=1, \mathrm{i}=300, \mathrm{j}=400$; float $\mathrm{k} 1=3.5 * \mathrm{k} 0, \mathrm{k} 2=5 * \mathrm{k} 0$;

int $\mathrm{p}, \mathrm{q}$;

$\mathrm{p}=\mathrm{n}+1-\mathrm{n} \% 3 ; \mathrm{q}=(\mathrm{n}+1) / 2-(\mathrm{n}-7) / 4 \% 2 ;$

float $\mathrm{xa}=\mathrm{k} 2 * \cos (2 * 3.14 *(\mathrm{p}) / \mathrm{n})-\mathrm{k} 2 * \cos (2 * 3.14 *(\mathrm{q}) / \mathrm{n})$;

float $\mathrm{ya}=\mathrm{k} 2 * \sin (2 * 3.14 *(\mathrm{q}) / \mathrm{n})-\mathrm{k} 2 * \sin (2 * 3.14 *(\mathrm{p}) / \mathrm{n})$;

for(int $\mathrm{i}=-40 ; \mathrm{i}<1400 ; \mathrm{i}+=2 * x \mathrm{x})$

for(int $\mathrm{j}=-100 ; \mathrm{j}<900 ; \mathrm{j}+=2 * \mathrm{k} 2 * \sin (((\mathrm{n}+1) / 4 * \operatorname{ang}) * 3.14 / 180)$.

\{

$\operatorname{rose}(\mathrm{k}, \mathrm{k} 0, \mathrm{k} 1, \mathrm{k} 2, \mathrm{n}, \mathrm{i}, \mathrm{j})$;

$\operatorname{rose}(\mathrm{k}, \mathrm{k} 0, \mathrm{k} 1, \mathrm{k} 2, \mathrm{n}, \mathrm{i}-\mathrm{xa}, \mathrm{j}+\mathrm{ya})$;

\}

$\operatorname{getch}()$;

closegraph();

\}

5. VARIATIONS ON THE SAME THEME

By changing the values of $n, k$ or $k 1$ in the main program we may generate a number of interesting star patterns.,

\section{VARIATION 1.}

Let $n=9$. Then the resulting output is illustrated in Figure 4 .

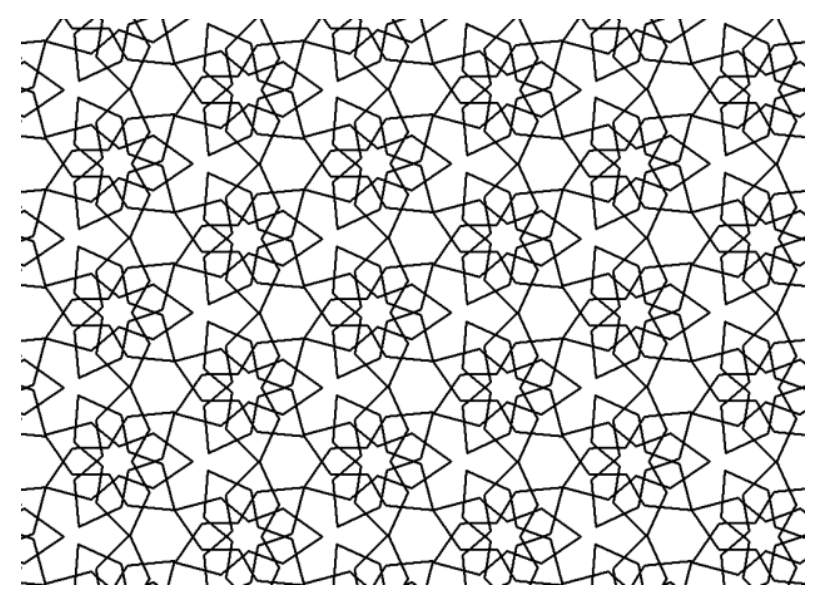

Fig. 4 : Variation 1 -

VARIATION 2.

Let $\mathrm{n}=9$ and $\mathrm{k} 0=4 \mathrm{xl}$. Then the resulting output is illustrated in Figure 5 .

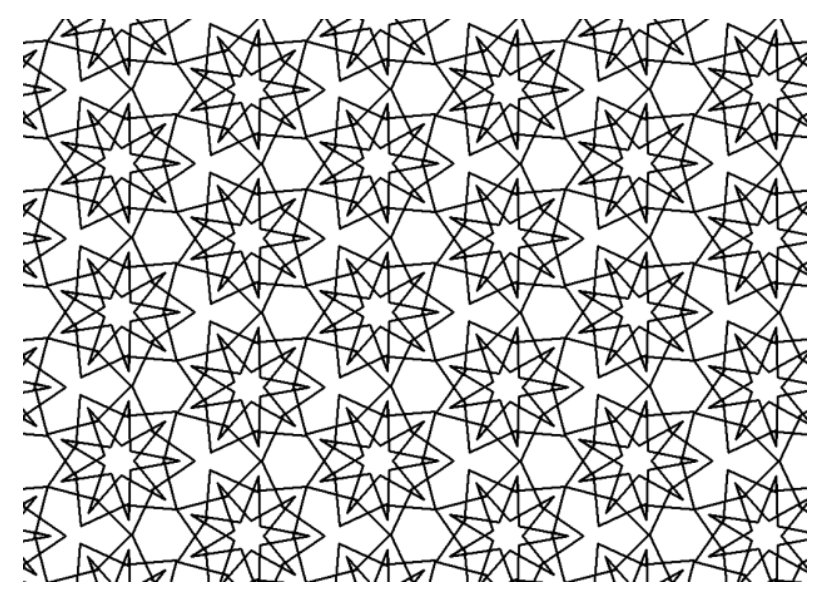

Fig. 5 : Variation 2

VARIATION 3.

Let $\mathrm{n}=9$ and $\mathrm{k} 1=2.5 \mathrm{xl}$; Then the resulting output is illustrated in Figure 6.

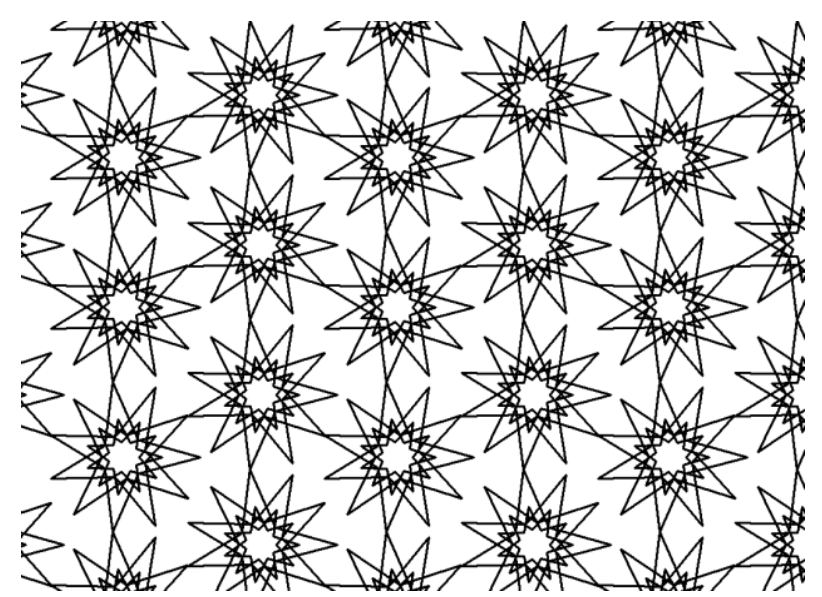

Fig. 6 : Variation 3 


\section{VARIATION 4.}

Let $\mathrm{n}=11$. By juxtaposing $\mathrm{k}=1.5 \times 1,3 \times 1$ and $4.5 \times 1$, we obtain the output illustrated in Figure 7.

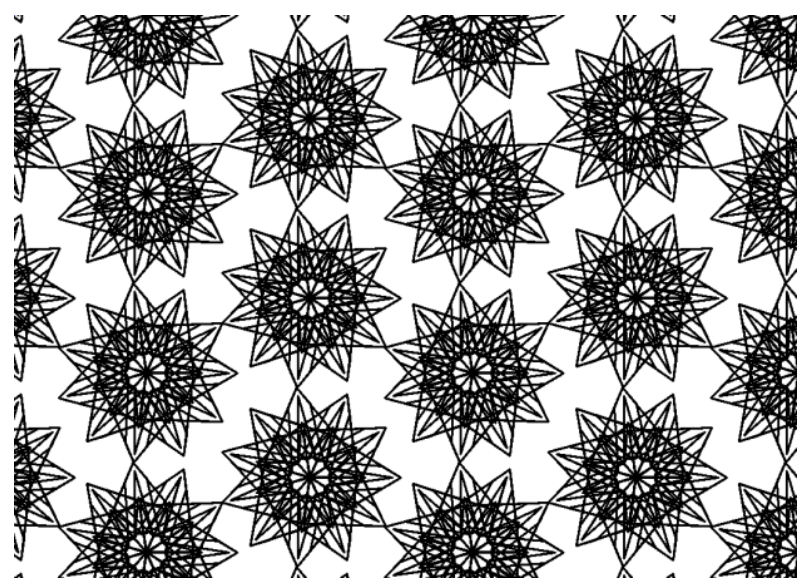

Fig. 7 : Variation 4

\section{VARIATION 5.}

Let $\mathrm{n}=11$. In addition to juxtaposing $\mathrm{k}=1.5 \mathrm{x} 1,3 \times 1$ and $4.5 \mathrm{x}$ 1 , if $\mathrm{k} 0$ is allowed to vary in a range and each cooresponding realization is coloured by the colour $\mathrm{k} 0$, then one obtains the output illustrated in Figure 8.

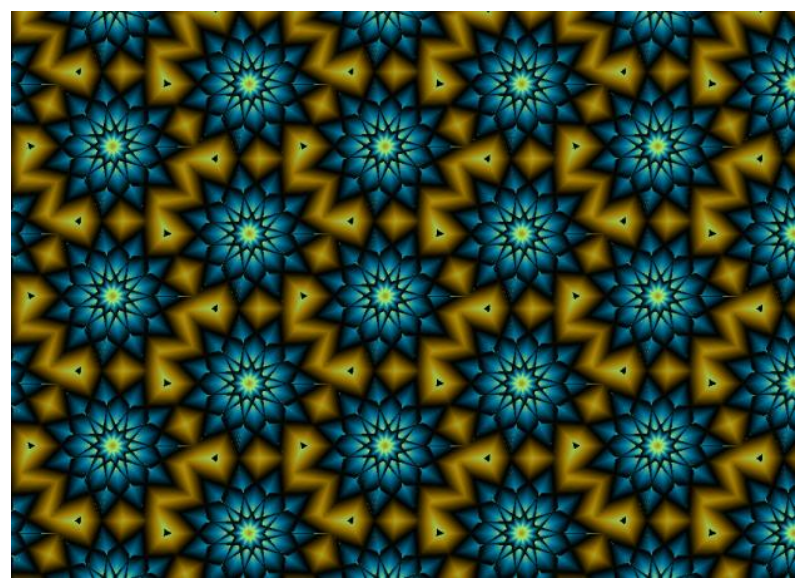

Fig. 8 : Variation 5

\section{AN ALTERNATE DESIGN}

An alternating diagonalized design is obtained by continuing the process of aligning the qth vertex of the old rosette with the pth vertex of the new one as described in section 3 for several iterations where $\mathrm{p}$ and $\mathrm{q}$ are as defined in section 3 . For instance, after four iterations we obtain the output illustrated in figure 9 .

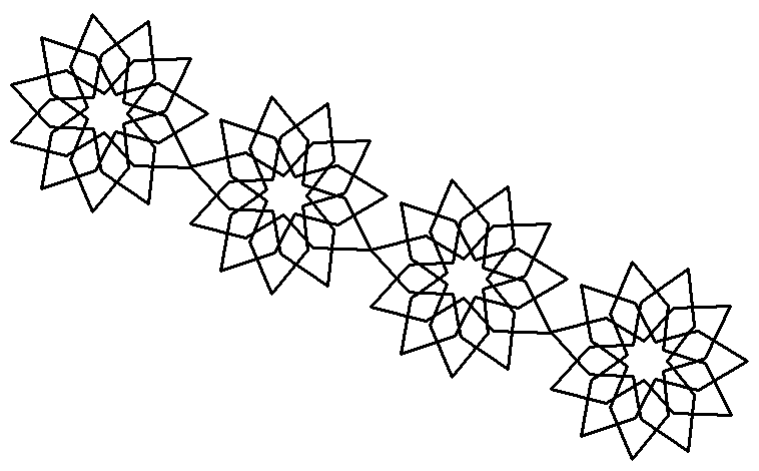

Fig. 9 : Two double rosettes

The image in Figure 9 is then repeated by increasing the ordinate of the centre of the first rosette $(\mathrm{n}, \mathrm{k}, \mathrm{k} 0, \mathrm{k} 1, \mathrm{k} 2)$ by $2(\mathrm{k} 2) \sin (((\mathrm{n}+1) / 4(\mathrm{ang})) \pi / 180$.). The main program in the code in section 4 above could be changed as follows to accommodate this new style of tiling

void main()

\{

initwindow(1040,760);

int $\mathrm{l}=20$;

int $\mathrm{k}=2.5^{*} 1$;int $\mathrm{n}=11$;float ang $=360 . / \mathrm{n}$;float $\mathrm{k} 0=1, \mathrm{i}=800, \mathrm{j}=400$; float $\mathrm{k} 1=3.5 * \mathrm{k} 0, \mathrm{k} 2=5 * \mathrm{k} 0$;

int $\mathrm{p}, \mathrm{q}$;

$\mathrm{p}=\mathrm{n}+1-\mathrm{n} \% 3 ; \mathrm{q}=(\mathrm{n}+1) / 2-(\mathrm{n}-7) / 4 \% 2$;

float $\mathrm{xa}=\mathrm{k} 2 * \cos (2 * 3.14 *(\mathrm{p}) / \mathrm{n})-\mathrm{k} 2 * \cos (2 * 3.14 *(\mathrm{q}) / \mathrm{n})$; float ya $=\mathrm{k} 2 * \sin (2 * 3.14 *(\mathrm{q}) / \mathrm{n})-\mathrm{k} 2 * \sin (2 * 3.14 *(\mathrm{p}) / \mathrm{n})$;

for $($ int $\mathrm{j}=-500 ; \mathrm{j}<900 ; \mathrm{j}+=2 * \mathrm{k} 2 * \sin (((\mathrm{n}+1) / 4 * a n g) * 3.14 / 180)$. for(int gn= $0 ; \mathrm{gn}<=9 ; \mathrm{gn}++)$

\{

rose $(\mathrm{k}, \mathrm{k} 0, \mathrm{k} 1, \mathrm{k} 2, \mathrm{n}, \mathrm{gn} * \mathrm{xa}, \mathrm{j}+\mathrm{gn} * \mathrm{ya})$;

\}

getch();

closegraph () ;

\}

The output of this is illustrated in Figure 10. One may compare Figure 10 to Figure 3. 


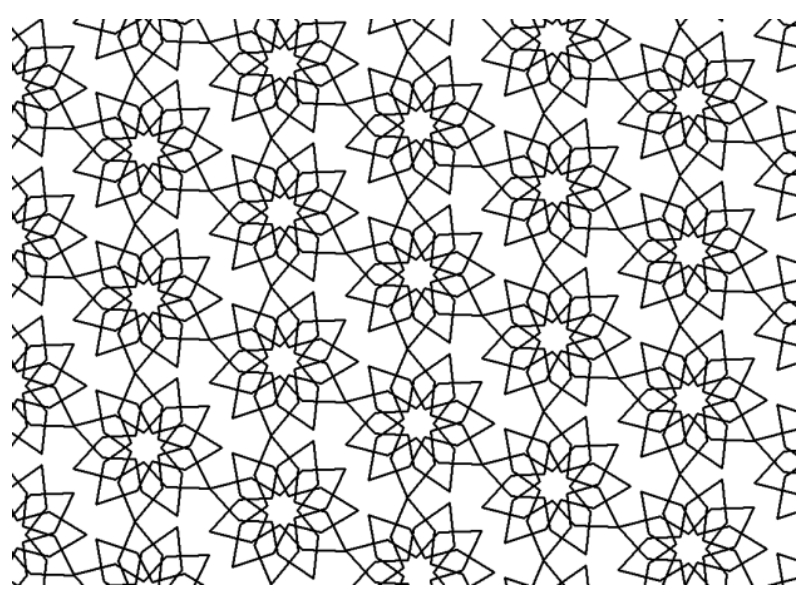

Fig. 10 : An alternate style of tiling

If $\mathrm{n}$ is 11 , the values of $\mathrm{k}=1.5 \times 1,3 \times 1$ and $4.5 \times 1$ are juxtaposed and $\mathrm{k} 0$ is varied in an appropriate range, then this new style of tiling yields the output given in Figure 11. One may compare this to Figure 8.

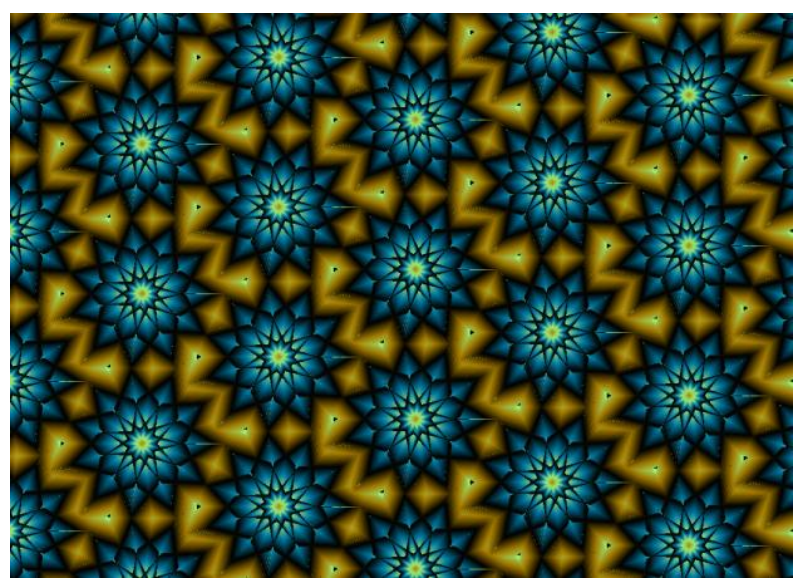

Fig. 11 : The new tiling with juxtaposition and colors

\section{7 . ALIGNING OTHER VERTICES}

If, in section 3 , instead of aligning the qth vertex of the first rosette with the pth vertex of the new one, we align the $(q+1)$ st vertex of the old rosette with the $(p+1)$ st vertex of the new one, then the tiling yields a different pattern for the original style and its alternate versions. The final output of these two altered styles are displayed respectively in figures 12 and 13 . They may be respectively compared to figures 8 and 11 and to each other.

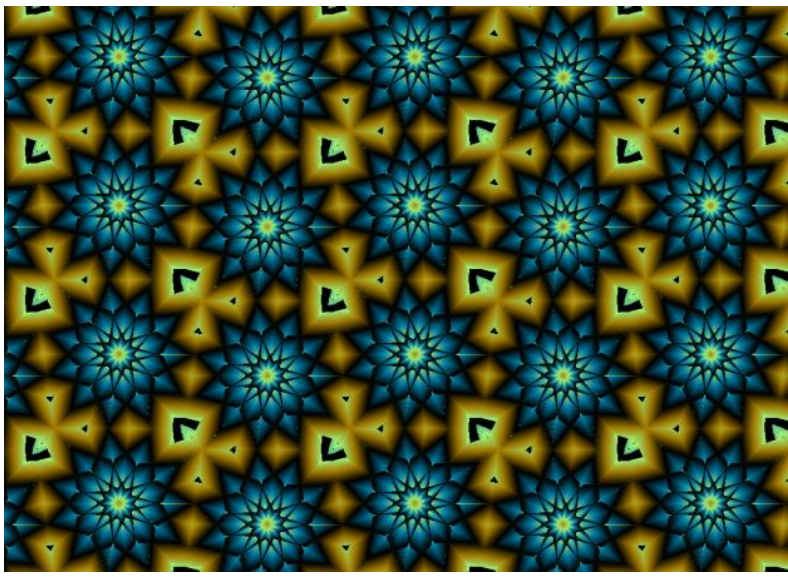

Fig. 12: The newly aligned original tiling

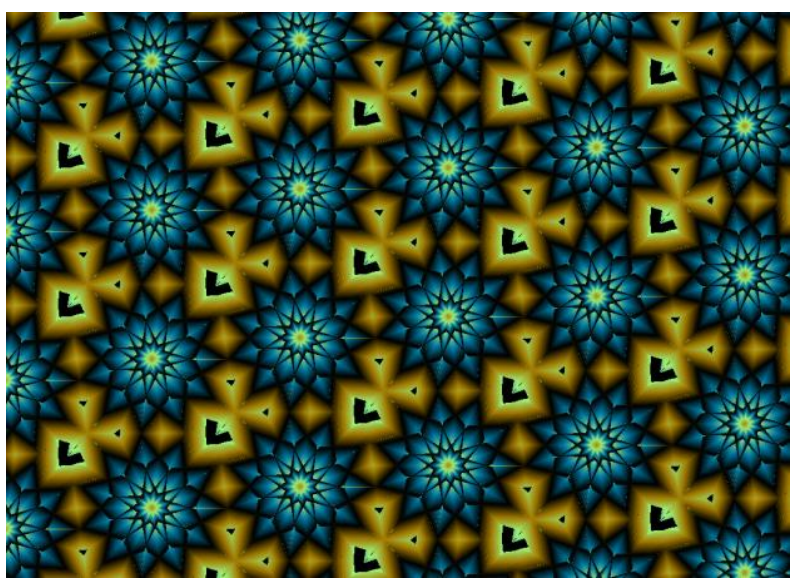

Fig. 13: The newly aligned alternate tiling

\section{CONCLUSION}

The tiling with with rosettes having a nonprime odd number of vertices may yield manifold symmetry.. This, as well as further new styles of tiling with even-vertexed rosettes would be explored in detail in future work.

\section{ACKNOWLEDGMENTS}

The author wishes to acknowledge his debt to the referee(s) for their constructive suggestions and encouragement

\section{REFERENCES}

[1] Syed Jan Abas and Amer Shaker Salman. Symmetries of Islamic Geometrical Patterns. World Scientific, 1995.

[2] J. Bourgoin. Arabic Geometrical Pattern and Design. Dover Publications, 1973.

[3] Jean-Marc Castera. Zellijs, muqarnas and quasicrystals. In Nathaniel Friedman and Javiar Barrallo, editors,ISAMA 99 Proceedings, pages 99-104, 1999. 1.

[4] Jean-Marc Castera et al. Arabesques: Decorative Art in Morocco. ACR Edition, 1999.

[5] A.K. Dewdney. The Tinkertoy Computer and Other Machinations, pages 222-230. W. H. Freeman, 1993. 
[6] Douglas Dunham. Artistic patterns in hyperbolic geometry. In Reza Sarhangi, editor, Bridges 1999 Proceedings, pages 139-149, 1999.

[7] Branko Gr"unbaum and G. C. Shephard. Tilings and Patterns. W. H. Freeman, 1987.

[8] Branko Gr"unbaum and G. C. Shephard. Interlace patterns in islamic and moorish art. Leonardo, 25:331$339,1992$.

[9] T. Gangopadhyay, On Tiling Patterns Involving Islamic Stars with an Odd Number of Vertices, International journal of computer applications, Vol. 65 , number 8,39 44.

[10] T. Gangopadhyay, Further Tiling Patterns Involving Islamic Stars with an Odd Number of Vertices, to be published in International journal of computer applications, April, 2013.
[11]T. Gangopadhyay, On Tiling Patterns Involving Islamic rosettes with an Odd Number of Vertices, submitted for publication to International journal of computer applications,.

[12] E.H. Hankin. Memoirs of the Archaeological Society of India, volume 15. Government of India, 1925.

[13] Craig S. Kaplan. Computer Generated Islamic Star Patterns. In Bridges 2000: Mathematical Connections in Art, Music and Science, 2000.

[14] Craig S. Kaplan and David H. Salesin. Islamic Star Patterns in Absolute Geometry. ACM Transactions on Graphics 23(2):97-119, April 2004.

[15] A.J. Lee. Islamic star patterns. Muqarnas, 4:182-197, 1995. 